\title{
Spectroscopic and thermogravimetric studies of homogeneous materials from PU/PMMA/SiO 2
}

\section{Estudios espectroscópicos y termogravimétricos de materiales homogéneos a partir de PU/PMMA/SiO}

\author{
RAMÍREZ-SALAS, Virginia ${ }^{1} \dagger^{*}$, ORDOÑEZ-PACHECO, Luis Daniel ${ }^{1}$, ALARCÓN-RUIZ, Erika $^{1}$ \\ and MORENO-MARTÍNEZ, Beatriz Eugenia ${ }^{1}$
}

\begin{abstract}
${ }^{1}$ Instituto Tecnológico de Ciudad Madero/Tecnológico Nacional de México, Departamento de Ingeniería Química y Bioquímica

${ }^{2}$ Instituto Tecnológico de Nuevo León/ Tecnológico Nacional de México, Departamento de Ingeniería Industrial
\end{abstract}

ID $1^{\text {st }}$ Author: Virginia, Ramírez-Salas / ORC ID: 0000-0002-0548-8653, CVU CONACYT ID: 173197

ID $1^{\text {st }}$ Coauthor: Luis Daniel, Ordoñez-Pacheco / CVU CONACYT ID: 844011

ID $2^{\text {nd }}$ Coauthor: Erika, Alarcon-Ruiz / CVU CONACYT ID: 163514

ID $3^{\text {rd }}$ Coauthor: Beatriz Eugenia, Moreno-Martinez / CVU CONACYT ID: 162379

DOI: $10.35429 /$ EJB.2020.13.7.18.23

Received: September 09, 2020; Accepted: December 04, 2020

\begin{abstract}
Polymers of organic-inorganic origin are incompatible by nature and a proposal to solve this behavior is the formation of Interpenetrated Polymeric Networks (IPN) using coupling agents. Coupling agents make it possible to create a crosslinking between the phases present that provides better mechanical, optical and thermal properties. These materials are known as Hybrid Networks. To obtain optically transparent materials, individual networks of Polyurethane (PU), Methyl Polyacrylate (PMMA) and Silica $\left(\mathrm{SiO}_{2}\right)$ were used. Binary and ternary networks were synthesized using bulk polymerization incorporating $\mathrm{SiO}_{2}$ up to $10 \%$ by weight. In this research, coupling agents such as Trimethoxysilyl Propyl Methacrylate (MSMA) and Isocyanotopropyl Triethoxy Silane (IPTS) were introduced to the ternary networks in order to reduce the phase separation that occurs in these systems. Fourier Transform Infrared Spectroscopy (FTIR) studies demonstrated the presence of functional groups of binary and ternary networks. On the other hand, the thermogravimetric tests (TGA) carried out on hybrid IPN's with coupling agents, presented greater thermal stability and better optical properties, providing the new IPN's with the opportunity to have promising applications.
\end{abstract}

Interpenetrated Networks, IPN's

\begin{abstract}
Resumen
Los polímeros de origen orgánico-inorgánico son incompatibles por naturaleza y una propuesta para solucionar este comportamiento es la formación de Redes Poliméricas Interpenetradas (RPI) utilizando agentes acoplantes. Los agentes acoplantes permiten crear entre las fases presentes un entrecruzamiento que proporciona mejores propiedades mecánicas, ópticas y térmicas. A estos materiales se les conoce como Redes Híbridas. Para obtener materiales ópticamente transparentes, se trabajaron con redes individuales de Poliuretano (PU), Polimetil metacrilato (PMMA) y Sílica $\left(\mathrm{SiO}_{2}\right)$. Se sintetizaron redes binarias y ternarias empleando la polimerización en masa incorporando $\mathrm{SiO}_{2}$ hasta en un $10 \%$ en peso. En esta investigación, se introdujeron agentes acoplantes como el Trimetoxisilil Propil Metacrilato (MSMA) y el Isocianotopropil Trietoxi Silano (IPTS) a las redes ternarias con el propósito de reducir la separación de fases que ocurre en estos sistemas. Los estudios de Espectroscopía Infrarroja por Transformada de Fourier (FTIR), demostraron la presencia de los grupos funcionales de las redes binarias y ternarias. Por otro lado, los ensayos termogravimétricos (TGA) realizados a las RPI's híbridas con agentes acoplantes, presentaron mayor estabilidad térmica y mejores propiedades ópticas, proporcionando a las nuevas RPI's la oportunidad de tener aplicaciones prometedoras.
\end{abstract}

Redes Interpenetradas, RPI's

Citation: RAMÍREZ-SALAS, Virginia, ORDOÑEZ-PACHECO, Luis Daniel, ALARCÓN-RUIZ, Erika and MORENOMARTÍNEZ, Beatriz Eugenia. Spectroscopic and thermogravimetric studies of homogeneous materials from PU/PMMA/SiO 2 . ECORFAN Journal-Bolivia. 2020. 7-13: 18-23

\footnotetext{
* Correspondence to Author (virginia.itcm.tecnm@gmail.com)

$\dagger$ Researcher contributing as first author.
} 


\section{Introduction}

The first polymeric networks were synthesized in the 20th century (Kausar, 2019). Interpenetrated Polymeric Networks are defined as Polymers that comprise two or more networks that are at least partially entangled on a molecular scale without covalent bonds with each other and cannot be separated unless the chemical bonds are broken (Kumar et al. 2018). Commonly, RPI's are prepared from a mixture of two monomers or polymers that are miscible. However, in this work, a network of inorganic origin has been incorporated, using coupling agents to obtain homogeneous materials that have better optical, mechanical and thermal properties; The formation of IPN's is a valuable strategy to reinforce and optimize the properties of a polymer network by combining a second network in it (Liang and Deng, 2017).

The first synthesis of mineral materials from polymerization reactions using molecular precursors of the metal alkoxide type was carried out by Ebelmen in 1845, obtaining with some gems such as sapphire, ruby and emerald (Sanchez et al, 1996). This method of manufacturing materials is known as the "solgel procedure", arousing strong interest for renewal both in the university community and in the industry.

The presence of organic composites makes it possible to modify the mechanical properties, produce films and fibers, obtain by simple molding various geometric structures for integrated optics, control porosity and adjust the hydrophilic / hydrophobic balance of the network. For their part, inorganic composites can play various roles, such as: contributing to increase the mechanical and thermal stress of the material, allowing the refractive index to be modulated, as well as adding electrochemical, magnetic and electrical properties (Babonneau et al., 1996). That is why the RPI's that are formed from organic / inorganic composites achieve excellent optical, thermal and mechanical properties.

The networks are classified according to the Interpenetration mode: if both polymeric systems are partially, semi or fully cross-linked.
The analysis of the properties of PU, PMMA and $\mathrm{SiO} 2$ is of vital importance, since PU has excellent elasticity, resistance to abrasion and damping properties (Kausar 2019); on the other hand, the crosslinked network of PMMA is an amorphous polymer that has high transparency and high mechanical resistance; finally, the $\mathrm{SiO} 2$ network, thus allowing the obtaining of a highly cross-linked inorganic network in an organic matrix without risk of decomposition or degradation.

In work carried out by Ghosh, (et. Al.) 2018 synthesized biodegradable and intelligent RPI's from PU, silicone and polystyrene, which exhibited good mechanical properties, biodegradability, impact resistance, scratch resistance as well as good thermal stability.

For its part, Bonilla, 2005, synthesized ternary hybrid materials, where the silica network obtained was synthesized from TEOS using the sol-gel method incorporating up to $37 \%$ by weight of TEOS, which upon polymerization formed a network of $\mathrm{SiO} 2$ improving the thermal stability of materials above $700^{\circ} \mathrm{C}$.

In this work, interesting results were obtained with respect to hybrid networks. The presence of an inorganic network can be considered as a protection for the organic network, because it raises the thermal decomposition temperature of the polymer. The thermal transition temperatures of the PU / $\mathrm{SiO} 2$ and PMMA / SiO2 hybrids are similar to that of the pure polymer. If a crosslinking agent (coupling agents) is added, the phase separation is lower and therefore its thermal stability is greater.

\section{Methodology (Bonilla, 2005)}

\section{Section 1. Synthesis}

The synthesis of the binary and ternary networks is presented below:

a) PU / PMMA network, the NCO, OH, MMA and TRIM monomers were mixed (with a 50/50 weight ratio) and $0.5 \%$ by weight of BPO was added for the formation of the PMMA network; DBTL was added for the formation of the PU network; 
b) $\mathrm{PU} / \mathrm{SiO} 2$ network, in ethyl acetate the monomers $\mathrm{NCO}, \mathrm{OH}$ and TEOS were dissolved (for $5,10,15 \%$ by weight of $\mathrm{SiO} 2$ in the final sample) and the PU catalyst, finally added the aqueous $\mathrm{HCl}$ solution;

c) PMMA / $\mathrm{SiO} 2$ network, at the beginning of the reaction the monomer MMA used as solvent for the rest of the components was added. TRIM and TEOS were homogenized $(5,10,15 \%$ by weight calculated). The initiator of the PMMA network was incorporated by magnetic stirring and finally the aqueous $\mathrm{HCl}$ solution was added;

d) PU / PMMA / SiO2 network without coupling agents. From previous studies, the highest quantity of TEOS incorporated in binary systems was obtained, with a 45/45/10 ratio by weight, the monomers $(\mathrm{NCO}, \mathrm{OH}$, MMA, TRIM and TEOS) were mixed by adding the network initiator of PMMA, the catalyst for the PU and the finally, the aqueous solution in the sol-gel processes of the TEOS were also incorporated;

e) PU / PMMA / SiO2 network with coupling agents, the coupling agents are $\square$ Isocyanate propyl triethoxy silane (IPTS) and 3- (trimethoxy silyl) propyl methacrylate (TSMA) as grafting agents for PU networks and PMMA, respectively, which were added at a maximum $4 \%$ by weight, for ternary networks.

\section{Section 2. Characterizations}

The RPIs that were formed were characterized by the techniques of: Fourier transform infrared spectroscopy (FTIR), thermogravimetric analysis (TGA). Fourier transform infrared spectroscopy (FTIR). The FTIR assays were obtained from a Perkin Elmer Spectrum One equipment with a resolution of $2 \mathrm{~cm}-1$ and 32 scans on $\mathrm{KBr}$ chip. On the other hand, the thermogravimetric analysis (TGA) was carried out in a TA Instruments Model SDT 2960 Simultaneous DSC-TGA equipment, with 20 $\mathrm{mg}$ of sample in an aluminum tray with a temperature ramp from Tamb to $800^{\circ} \mathrm{C}$, with a heating rate $5^{\circ} \mathrm{C} / \mathrm{min}$ in nitrogen atmosphere

\section{Results}

\section{Section 1}

Table 1 shows the results of the binary RPIs of $\mathrm{PU} / \mathrm{SiO} 2$ at different concentrations of TEOS. Table 2 shows the results of the PMMA / SiO2 networks. Table 3 shows the results of the RPI's of PU / PMMA / SiO2 at different concentrations of TEOS with and without coupling agents.

\begin{tabular}{|l|l|l|}
\hline \multicolumn{2}{|c|}{$\%$ in weigh } & Appearance of the sample \\
\hline PU & TEOS & \\
\hline 95 & 5 & Translucent, flexible \\
\hline 90 & 10 & Translucent, soft-rubbery \\
\hline 85 & 15 & Translucent, rubbery \\
\hline 80 & 20 & Appearance of the sample \\
\hline
\end{tabular}

Table 1 RPI's of PU / SiO2 at different concentrations of TEOS

Own Source

\begin{tabular}{|l|l|l|}
\hline \multicolumn{2}{|l}{$\%$ in weigh } & Appearance of the sample \\
\hline PMMA & TEOS & \\
\hline 95 & 5 & Translucent, rigid \\
\hline 90 & 10 & Translucent, rigid \\
\hline 85 & 15 & Opaque, semi-rigid \\
\hline 80 & 20 & Opaque-White, fragile \\
\hline
\end{tabular}

Table 2 RPI's of PMMA / $\mathrm{SiO} 2$ at different concentrations of TEOS

Own Source

\begin{tabular}{|l|l|l|l|l|l|}
\hline \multicolumn{7}{|c|}{ \% in weigh } \\
\cline { 1 - 5 } PU & PMMA & TEOS & IPTS & TSMA & Ap \\
\hline 45 & 45 & 10 & - & - & $* \mathrm{Tr} / \mathrm{Sr}$ \\
\hline 41 & 41 & 10 & 4 & 4 & $* \mathrm{Tr} / \mathrm{Sr}$ \\
\hline
\end{tabular}

Table 3 RPI's of PU / PMMA / $\mathrm{SiO} 2$ at different concentrations of TEOS and coupling agents (IPTS, TSMA), Ap. Aspect, * Translucent, semi-rigid (Tr/ Sr) Own Source

\section{Section 2}

\section{Infrared spectroscopy (FTIR)}

The results obtained from the FTIR tests are described below: i) Figure 1 FTIR spectrum for PU / SiO2 binary RPIs: a) 95/5, b) 90/10 and c) $85 / 15 \%$ in weight; ii) Figure 2 FTIR spectrum for the PMMA / SiO2 network: a) 95/5, b) $90 / 10$ and c) $85 / 15 \%$ by weight; iii) figure 3 FTIR spectrum for the PU / PMMA / SiO2 system in a range of 4000-500 cm-1 and ternary with and without coupling agents ternary with and without coupling agents. In Figure 1, the infrared spectrum of the PU system network with 5,10 and $15 \%$ by weight of $\mathrm{SiO} 2$ is observed. 
The presence of representative groups of $\mathrm{PU}$ and $\mathrm{SiO} 2$ in the three spectra is remarkable. The three compositions of TEOS to form the silica network indicate that the inorganic network was formed in the polyurethane network; the representative bands of the inorganic network (SiO2) at 1103-1079, 789751 and 585-507 cm-1. The band of the urethane group at $1468 \mathrm{~cm}-1$ corresponds to the $\mathrm{N}-\mathrm{H}$ bending. The carbonyl group attached to the monosubstituted amine (-CO-NH-) at 1526 $\mathrm{cm}-1$. The bending and stretching of the carbonyl group $(\mathrm{C}=\mathrm{O})$ is at $1742 \mathrm{~cm}-1$.

The peaks representing the $\mathrm{C}-\mathrm{H}$ asymmetric stretching are observed in the range of 2987-2822 cm-1, corroborating their appearance at $1320-1362 \mathrm{~cm}-1$. In figure 2 , the characteristic bands of the PMMA network show the stretching of the methyl groups (CH3) at 2994 and methylenes (-CH2) at 2942 $\mathrm{cm}-1$, corroborating their appearance at 1470 $\mathrm{cm}-1$ and $1738 \mathrm{~cm}-1$ the carbonyl group band $(\mathrm{C}=\mathrm{O})$ is observed, assigned to the ester group of the PMMA chain. The characteristic peaks for the Si-O-Si bonds are at 1214-1120, 852$748 \mathrm{~cm}-1$ and $516-490 \mathrm{~cm}-1$; $\mathrm{OH}$ groups are found in the $3300-3700 \mathrm{~cm}-1$ and $950-1008 \mathrm{~cm}-$ 1 region.

Apparently, the three spectra of the samples do not show great changes, however, in figure 2 c) a shoulder is detected at 1640-1547 $\mathrm{cm}-1$ that is not observed in figures $2 \mathrm{a}$ ) and b) and is attributed to silanol groups in the medium, produced by the nature of the polyol and by the higher concentration of TEOS that favors the formation of these.

It should be mentioned that these materials improved their appearance by introducing coupling agents. For the synthesis of these networks, the same conditions of the binary networks were taken obtaining the ternary system resulting in semi-rigid IPN's, with a better formation of the inorganic network, which was observed in the TGA analyzes in section 2 showing a residual weight of $10 \%$ in silica, this is attributed to the fact that the inorganic network and the coupling agents provide greater crosslinking to the system and consequently greater thermal stability.

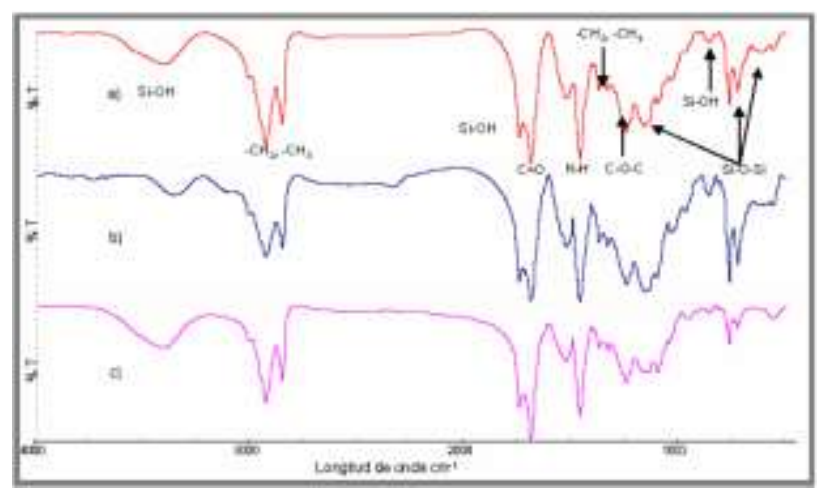

Figure 1 FTIR spectrum for the PU / SiO2 network: a) $95 / 5$, b) $90 / 10$ and c) $85 / 15 \%$ by weight Own Source

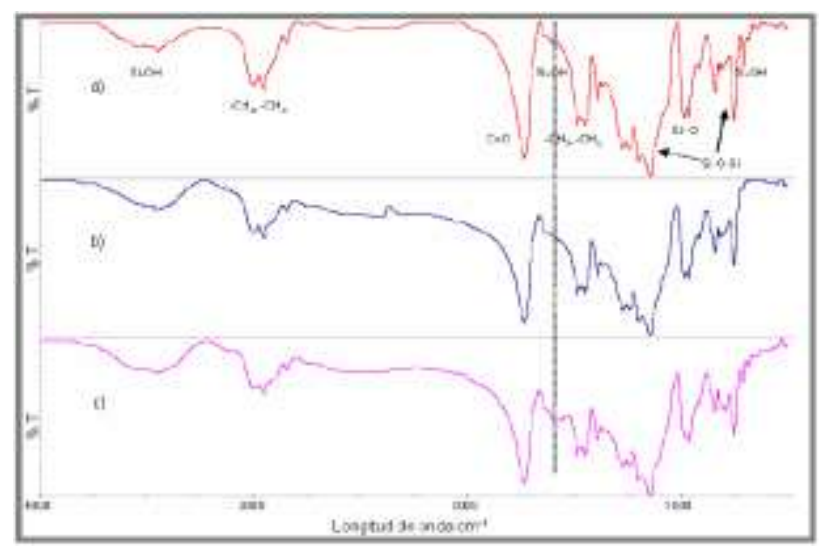

Figure 2 FTIR spectrum for PMMA / $\mathrm{SiO} 2$ network: a) $95 / 5$, b) $90 / 10$ and c) $85 / 15 \%$ by weight

Finally, Figure 3 shows the infrared spectrum of the ternary network incorporating into the organic system an amount of TEOS of $10 \%$ of the total weight calculated for the network and $4 \%$ by weight of the coupling agents. The spectra shown represent the characteristic functional groups of the ternary network without agents and with coupling agents. In the region of 3200-3670 and 940$1002 \mathrm{~cm}-1$, of both spectra, are the bands attributed to the $-\mathrm{OH}$ groups, these originate from the $\mathrm{OH}$ 's of the polyol and residual silanol.

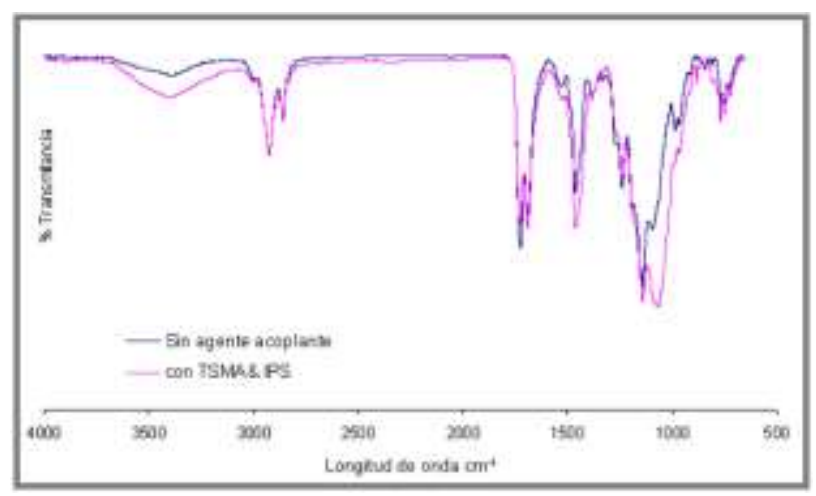

Figure 8 FTIR spectrum for PU / PMMA / SiO2 system in TSMA and IPS

RAMÍREZ-SALAS, Virginia, ORDOÑEZ-PACHECO, Luis Daniel, ALARCÓN-RUIZ, Erika and MORENO-MARTÍNEZ, Beatriz Eugenia. Spectroscopic and thermogravimetric studies of homogeneous materials from PU/PMMA/SiO 2 . ECORFAN Journal-Bolivia. 2020 


\section{Thermogravimetric Analysis (TGA)}

In thermogravimetry (TGA), for a cross-linked polymer, an increase in temperature causes the molecular motion to increase until the polymer molecules degrade. This process occurs in stages, when a substance is heated to different temperatures undergoes a series of transformations, which are attributed to changes in the mass of said substance.

The characterized samples correspond to the binary and ternary hybrid systems with and without coupling agents. Figure 4 represents the TGA of the PU / SiO2 network with 95/5, 90/10, 85/15. Observing the characteristic behavior for the organic network considering that when reaching $500^{\circ} \mathrm{C}$ all the organic part has degraded and after this temperature the residual weight corresponds to a silica network.

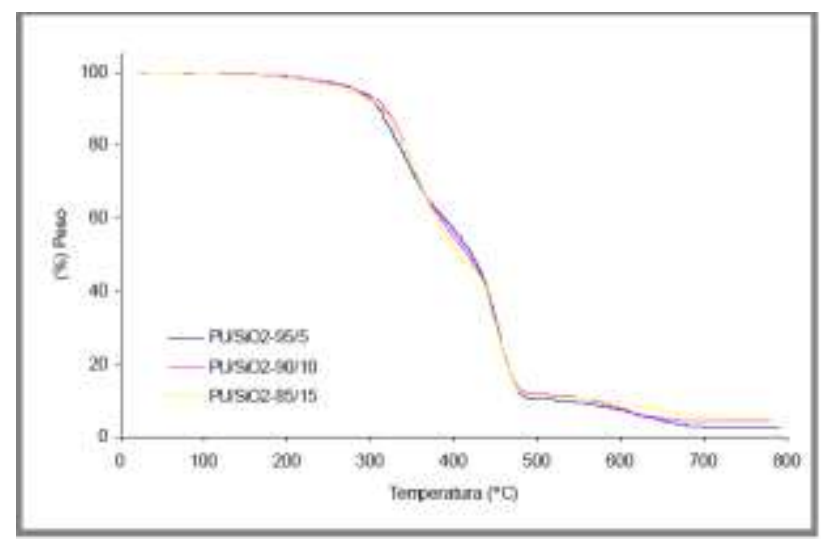

Figure 4 PU / SiO2 binary network thermogram

Figure 5 shows the TGA thermogram of the PMM / SiO2 binary network, where the thermal stability of the sample is close to 800 ${ }^{\circ} \mathrm{C}$. It can be seen that the curve that represents the IPN of PMMA / SiO2 whose ratio is 90/10 presents a greater resistance to thermal decomposition, since all the organic part at a temperature close to $400{ }^{\circ} \mathrm{C}$ has decomposed; additionally, the optical properties of the sample were better compared to the samples whose PMMA / SiO2 ratio is 95/5 and 85/15. With the above we can consider that above $500{ }^{\circ} \mathrm{C}$ is only the silica network.

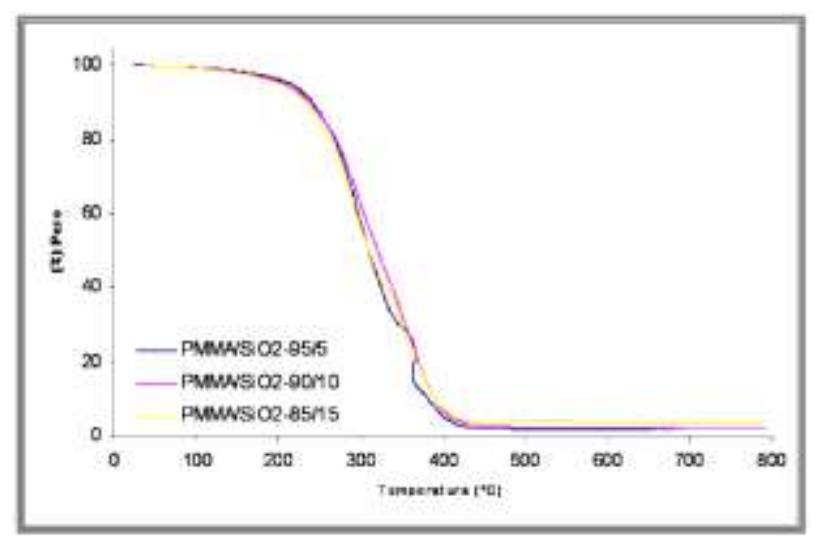

Figure 5 Thermogram of a PMMA / SiO2 network

Figure 6 corresponds to a PU / PMMA / $\mathrm{SiO} 2$ thermogram, in this it is possible to appreciate the ternary network whose final concentration corresponds to 45/45/10 and $41 / 41$ / 10-4\% with IPTS and MSMA. It is observed that the loss in weight up to $200{ }^{\circ} \mathrm{C}$ is very small, this is attributed to the fact that the humidity in the material is very little, but from $245-378^{\circ} \mathrm{C}$ there is a significant loss in weight; In this first stage, the soft segments of PU, CO2 pyrolysis and PMMA can be decomposed in the two curves with and without agents. In a second stage, the ternary IPN that does not contain coupling agents presents a shoulder in a range of $378-464{ }^{\circ} \mathrm{C}$ that can be caused by the thermal decomposition of secondary organic products such as polyurea that it was possible to observe in the infrared spectra, the segments rigid PU, hydroxyl groups and complete decomposition of PMMA.

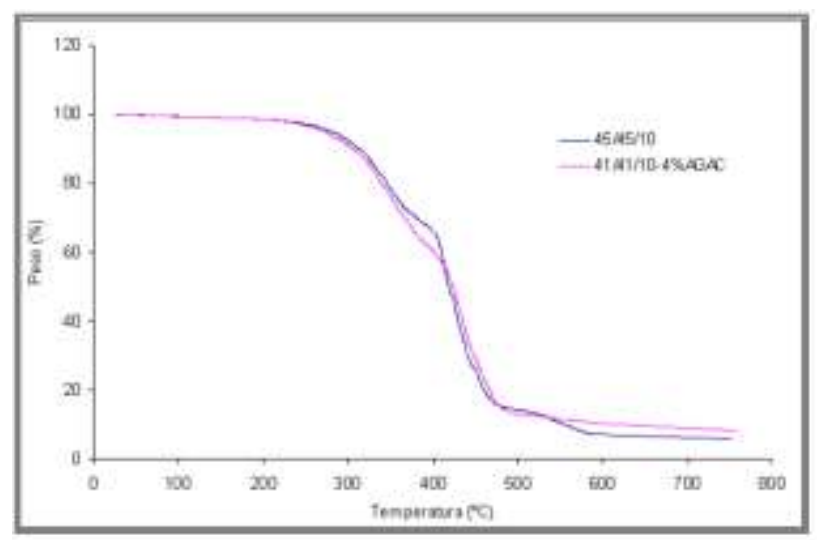

Figure 6 TGA of PU / PMMA / SiO2 ternary networks

\section{Acknowledgments}

We thank the Tecnológico Nacional de México for the facilities granted to carry out this project, in particular the Instituto Tecnológico de Ciudad Madero and the Instituto Tecnológico de Nuevo León. 


\section{Conclusions}

In the FTIR studies, the representative groups of each system were observed, where the appearance of various bands attributed to silanol (Si-OH) indicate that a partial conversion of silica was obtained. The IPN synthesized without coupling agents presented its thermal stability very close to $800{ }^{\circ} \mathrm{C}$ with a residual weight of $7 \%$, which is attributed solely to the $\mathrm{SiO} 2$ network since it is considered that all the organic part decomposed around $500{ }^{\circ} \mathrm{C}$.

However, the use of coupling agents increased said stability, manifesting a higher residual weight in the $\mathrm{SiO} 2$ content of $10.58 \%$, this is due to the fact that these agents contain within their chemical structure, Si-O groups that increase the active sites for generate the polymerization of the inorganic network in addition to TEOS, causing the network to obtain a higher residual weight of silica.

The tests carried out on the ternary IPNs revealed that by incorporating the three networks in a single system, they affect four important points: 1) formation of secondary products, 2) the thermal stability of the materials, 3) homogeneity of the systems and 4) mechanical properties.

\section{References}

Babonneau, F., Sanchez C., (1996) "Stratégies de Synthèse des Matériaux Hybrides", ed. Masson, Paris, 33-55.

Bonilla, M., G. A., (2005),"Réseaux Hybrides Interpénétrés", Instituto Charles Sadron, Estrasburgo, Francia, 5-15, 77- 89, 115-150.

Dave, V. J., Patel, H. S., (2013), "Synthesis and Characterization of interpenetrating Polymer Networks from Transesterified Castor Oil Based Polyurethane and Polystyrene", 1-7.

Ghosh, T., Karak, N., (2018) "Tough Interpenetrating Polymer Network Of Silicone Containing polyurethane and polystyrene with Self-healing, shape memory and self-cleaning attributes" Royal Society of Chemistry.

Hahn, W., (1985) "Polyurethane Handbook", 2ed., Hanser, Munich,11-16, 33-37, 55-56, 6569.
Kausar, A., 2019 "Interpenetrating polymer network and nanocomposite IPN of polyurethane/epoxy: a review on fundamentals and advancements" Polymer-Plastics Technology and Materials.

Kumar, Mihir Purkait, Kumar Manish, Sinha Mondal Piyal, Singh Randeep, "Stimuli responsive Polymeric Membranes: Interpenetrating Polymer Networks 2019 Volume 25, Pages 67-113

Liang, J., Deng J., (2017), "Chiral Interpenetrating Polymer Network Constructed by Helical Substituted Polyacetylenes and Used for Glucose Adsorption", 1-7.

Mazo, P. C., Restrepo, G., Estenoz, D., (2006 ) "Síntesis y caracterización de espumas de Poliuretano utilizando aceites vegetales: XIV Congreso colombiano de química".

Olvera, I.V., Armenta, R.J.L., Antonio, C.R.C., Mendoza, M.A.M, (2007), "Comportamiento térmico de IPN's de PU/PMMA modificados con cargas inorgánicas", Revista Iberoamericana de Polímeros, vol. 8(4), p. 313322

Pretsch, E., Cler, T., Seibl, J., Simon, (1996,) "Tablas para la elucidación estructural de compuestos orgánicos por métodos espectroscópicos", Alambra Longman, España, I.5 - I.250.

Sanchez C., (1996) "Les Matériaux Hybrides: Définition et Classification". Ed. Masson, Paris, 17-19, 27-31. 